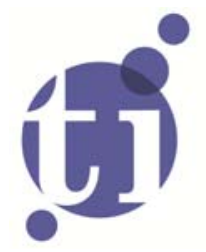

\title{
Efficiency Effects of Unit-based Pricing Systems and Institutional Choices of Waste Collection
}

Elbert Dijkgraaf

Raymond Gradus ${ }^{2}$

${ }^{\prime}$ Erasmus School of Economics, Erasmus University Rotterdam, and Tinbergen Institute, The Netherlands;

2 Faculty of Economics and Business Administration, VU University Amsterdam, The Netherlands. 
Tinbergen Institute is the graduate school and research institute in economics of Erasmus University Rotterdam, the University of Amsterdam and VU University Amsterdam.

More TI discussion papers can be downloaded at http://www.tinbergen.nl

Tinbergen Institute has two locations:

Tinbergen Institute Amsterdam

Gustav Mahlerplein 117

1082 MS Amsterdam

The Netherlands

Tel.: +31(0)205251600

Tinbergen Institute Rotterdam

Burg. Oudlaan 50

3062 PA Rotterdam

The Netherlands

Tel.: +31(0)10 4088900

Fax: $+31(0) 104089031$

Duisenberg school of finance is a collaboration of the Dutch financial sector and universities, with the ambition to support innovative research and offer top quality academic education in core areas of finance.

DSF research papers can be downloaded at: http://www.dsf.nl/

Duisenberg school of finance

Gustav Mahlerplein 117

1082 MS Amsterdam

The Netherlands

Tel.: +31(0)20 5258579 
Efficiency effects of unit-based pricing systems and institutional choices of waste collection

January 3, 2014

\section{Elbert Dijkgraaf}

Rotterdam School of Economics, Erasmus University Rotterdam, P.O. Box 1738, 3000 DR Rotterdam, and Tinbergen Institute, The Netherlands, Email: dijkgraaf@ese.eur.nl

\section{Raymond Gradus ${ }^{\#}$}

VU University Amsterdam, Faculty of Economics and Business Administration, De Boelelaan 1105, 1081 HV Amsterdam, The Netherlands, Email: rgradus@feweb.vu.nl \# Corresponding author

\section{Abstract}

Much attention has been paid to the influence of the institutional form of waste collection on costs. We extend this literature in three directions by including the unit-based pricing system. First, we show that unit-based pricing systems are more important from a cost-minimizing point of view than the institutional mode of waste collection. In particular, the bag-based and frequency-based pricing systems are preferred. Second, dividing the cost effects between price and quantity effects, we illustrate that lower administrative costs and a smaller waste quantity are the most important drivers of cost decreases. It also shows that a disadvantage of the bag-based system is that it is not easy to price compostable waste. Third, if more general cost functions are analyzed, these estimations suggest that there are economies of scale for small municipalities.

JEL classification: $\mathrm{H} 31 ; \mathrm{H} 71 ; \mathrm{Q} 38$.

Keywords: waste collection; cost functions; efficiency; unit-based pricing; contracting out. 


\section{Introduction}

There is a large literature discussing the economic performance of waste services. Simões and Marques (2012) show that, in more than 100 papers, cost or performance functions are estimated in the context of discussing the efficiency of municipal waste services. Most of these studies look at the so-called public-private dichotomy in solid waste collection, as there was some evidence in the early literature that private delivery provides efficient services well adapted to needs and a reduction in the costs to the taxpayer. In an overview article, Domberger and Jensen (1997) show that private production suggests cost savings of the order of $20 \%$ without sacrificing the quality of service provided for a number of government services. However, the current evidence for cost savings from private delivery is more mixed. In a recent overview article, Bel et al. (2010a) conduct a meta-regression analysis, dominated by the refuse collection literature, and show that there is no unambiguous evidence for obtaining significant cost savings from private production.

Therefore, the recent literature gives more attention to inter-municipal cooperation (for a recent overview, see Bel and Warner (2013)). In addition, based on Dutch data, Dijkgraaf and Gradus (2013) show that the cost advantage of inter-municipal cooperation is larger than that of privatization. Interestingly, there are large differences between omitting and including municipal fixed effects. For private companies, the cost advantage is substantially smaller and non-significant if municipal fixed effects are taken into account. So, the overall conclusions should be that it is important to include fixed effects at the municipal level. Moreover, one should be skeptical about the reported effects of privatization in studies without fixed effects.

Almost separately, other instruments are implemented to achieve waste reduction and decrease the costs of waste collection. In order to promote waste prevention and recycling, an increasing number of municipalities in the United States, the European Union and Japan have introduced a unit-based pricing system (for a recent overview, see Usui and Takeuchi (2013)). This is also the case for the Netherlands. Starting from 15\% in 1998, the percentage of Dutch municipalities using such a system was 37\% in 2012. Dutch municipalities have introduced different types of unit-based pricing systems. Four such systems can be distinguished: volume-, frequency-, bag- and weight-based. Using Dutch municipal data, sizeable and significant effects on the amount of unsorted waste from the different unit-based pricing systems are found (see Dijkgraaf and Gradus (2004, 2009 and 2014) and Allers and Hoeben (2010)). In Allers and Hoeben (2010) and Dijkgraaf and Gradus (2014), a fixed effect at the 
municipal level is used and, as a consequence, the effects of unit-based pricing systems are somewhat lower but still remain large.

Remarkably, the literature has given less emphasis to other elements such as the effects of unit-based pricing or recycling policies on costs. Simões and Marques (2012) notice that there is not much attention given to discussing the relationship between costs and recycling, disposal and incineration. ${ }^{1}$ Therefore, we include unit-based pricing systems in our cost functions. Indeed, unit-based pricing may reduce garbage quantities and increase recycling, but measuring waste quantities and billing households is costly. It will be shown that from a cost perspective, the introduction of unit-based pricing systems (especially frequency- and bag-based) is more important than the institutional mode of waste collection. Including the different unit-based pricing systems as explanatory variables in cost function estimation has an additional advantage. As administrative costs differ significantly between the systems, it is interesting to know which system is preferred from a cost-minimizing perspective. We also divide this cost effect between price and quantity effects. These quantity effects are important when comparing our results with the previous literature and it can be put forward that a weight-based pricing system is preferable from a quantity point of view but not from a price point of view. In addition, we distinguish the quantity effect between different waste streams.

In this paper, we try to investigate scale effects as well. Stevens (1978) emphasizes the importance of differentiating between small, medium-sized and large municipalities. Also, early Dutch empirical evidence indicates that scale economies exist in this service for populations of fewer than 40,000 inhabitants (see also Dijkgraaf and Gradus (2003)). However, it is important to check whether most small Dutch municipalities still fall below this optimal size, as more flexible organizational forms (such as cooperation and municipalityowned firms) are used in order to address the scale problem. By using different production technologies in a translog or a Fourier specification, we give some indication that Dutch municipalities already make use of this scale effect. Only for very small municipalities are there some scale effects.

\footnotetext{
${ }^{1}$ An exemption is Callan and Thomas (2001). They estimate a cost function for disposal and recycling simultaneously. They found economies of scope between disposal and recycling. However, as we do not have separate cost data for disposal and recycling it is not possible to apply this approach.
} 
The paper is organized as follows. In section 2, data and method are discussed. In section 3, estimation results are given. In section 4, the cost effects are divided between price and quantity effects. In section 5, different production technologies are estimated. Finally, section 6 contains some conclusions.

\section{Method and data}

In this paper, we estimate the following cost function: ${ }^{2}$

$\ln T C_{i}=f\left(\ln Q_{i}, \ln I_{i}, \ln S_{i}, O_{N}, O_{C}, O_{P}, O_{O}, O_{I}, U B P_{s}, a_{i}, b_{t}\right)+\varepsilon_{i}$

where $T C_{i}$ are the (total) waste costs per household in municipality $i$. Comparison of total costs between municipalities is only possible when a correction is made for all relevant differences in exogenous factors. Most of the factors we use follow directly from the literature that estimates cost functions for waste collection (see, for example, Dijkgraaf and Gradus (2013)). Total costs will change:

- $\quad$ if the number of stops made by the collection vehicle increases $\left(Q_{i}\right.$ is the number of pick-up points in municipality $i$, measured as the number of households);

- $\quad$ if the time spent at each pick-up stop increases (more bags or bins) ( $I_{i}$ is the number of inhabitants per pick-up point);

- $\quad$ if the time to arrive at the different pick-up points increases $\left(S_{i}\right.$ is the area served per pick-up point);

- $\quad$ if the institutional form in which waste is collected changes $\left(O_{N}\right.$ is a dummy with value 1 for municipalities where waste is collected by a neighboring municipality, $O_{C}$ is a dummy with value 1 for municipalities that collect waste in cooperation with other (neighboring) municipalities, $O_{P}$ is a dummy with value 1 for municipalities that use a private collection firm, $O_{O}$ is a dummy with value 1 for municipalities that use a municipality-owned firm and $O_{I}$ is a dummy with value 1 for municipalities that collect waste themselves);

- $\quad$ as the time-invariant municipal fixed effects $\left(a_{i}\right)$ change; therefore we include fixed effects at the municipal level; ${ }^{3}$

- $\quad$ as the time fixed effects $\left(b_{t}\right)$ change; therefore we include a fixed effect for each year.

\footnotetext{
${ }^{2}$ Price variables for the different inputs are not included as there is no ex ante reason for factor prices to differ between municipalities. Wage bargaining takes place at a national level.

${ }^{3}$ For convenience, we do not present the estimation of these dummies in the tables. They are available on request.
} 
Importantly, we include whether municipalities have introduced unit-based pricing systems $\left(U B P_{s}\right.$ are dummies with the value 1 for municipalities that use a unit-based pricing system of type $s$ (volume, frequency, bags and weight)).

We have data for 551 municipalities for the period 1998-2012, with a total of 6,694 observations. ${ }^{4}$ Institutional and cost data on waste collection come from Agentschap NL. TC is calculated for each municipality by multiplying the average cost per household by the number of households. ${ }^{5} T C$ is in real terms as we correct for price developments on the basis of the index of consumer prices. Data for the socio-economic characteristics come from Statistics Netherlands (CBS). For descriptive statistics, see Table 1.

Table 1. Descriptive statistics

\begin{tabular}{lrrrrrr}
\hline & Mean & Maximum & Minimum & $\begin{array}{r}\text { Standard } \\
\text { deviation }\end{array}$ & $\begin{array}{c}\text { Observations } \\
\text { sections }\end{array}$ \\
\hline Costs (total) & $3,453,417$ & $131,656,617$ & 100,838 & $7,165,474$ & 6,655 & 551 \\
Households & 14,620 & 436,756 & 400 & 28,922 & 6,655 & 551 \\
Household size & 2.48 & 3.70 & 1.68 & 0.21 & 6,655 & 551 \\
Population density & 13,236 & 789,475 & 334 & 37,079 & 6,655 & 551 \\
UBP volume & 7.08 & 100.00 & 0.00 & 25.65 & 6,655 & 551 \\
UBP frequency & 12.70 & 100.00 & 0.00 & 33.30 & 6,655 & 551 \\
UBP bag & 4.07 & 100.00 & 0.00 & 19.77 & 6,655 & 551 \\
UBP weight & 4.37 & 100.00 & 0.00 & 20.45 & 6,655 & 551 \\
UBP activism & 14.38 & 100.00 & 0.00 & 35.09 & 6,655 & 551 \\
US & 15.38 & 23.00 & 0.00 & 2.66 & 3,034 & 508 \\
Collection by neighbor & 3.37 & 100.00 & 0.00 & 18.04 & 6,655 & 551 \\
Collection cooperation & 15.45 & 100.00 & 0.00 & 36.14 & 6,655 & 551 \\
Collection MOF & 22.96 & 100.00 & 0.00 & 42.06 & 6,655 & 551 \\
Collection private & 36.20 & 100.00 & 0.00 & 48.06 & 6,655 & 551 \\
Waste total & 13,663 & 307,096 & 530 & 20,907 & 4,942 & 530 \\
Waste unsorted & 7,781 & 258,071 & 280 & 16,426 & 4,942 & 530 \\
Waste biodegradable & 2,881 & 21,092 & 31 & 2,566 & 4,942 & 530 \\
Waste paper, glass and textiles & 3,001 & 42,812 & 23 & 3,360 & 4,942 & 530 \\
Price (euro/kg/inhabitant) & 0.23 & 0.55 & 0.09 & 0.05 & 4,942 & 530 \\
\hline I & & & & & &
\end{tabular}

1. MOF stands for municipality-owned firms

\footnotetext{
${ }^{4}$ The number of municipalities decreased from 548 in 1998 to 431 in 2010. For 1998, data are available on $72 \%$ of the municipalities. From 2001, data on almost all municipalities (more than 95\%) are available. For some small merged municipalities, data are only available in a couple of years.

${ }^{5}$ Agentschap $N L$ presents figures on actual tariffs for collecting and disposing of garbage and on the extent to which these tariffs cover total costs. If actual tariffs do not cover total costs, we use coverage factors (provided by Agentschap NL) to calculate cost-covering tariffs.
} 
Most of the empirical literature uses a Cobb-Douglas technology to describe the cost function. In equation (1), we have used a more general production technology $f$. It is well known that, after taking logarithms, a Cobb-Douglas technology facilitates the empirical estimation and its interpretation. However, it assumes constant scale effects (for derivation, see Stevens (1978), for example), which can be too restrictive. Therefore, in this paper, we evaluate more general production functions. The Cobb-Douglas function will be used in sections 3 and 4 and more general production technologies as translog, Fourier and flexible technologies will be investigated in section 5 .

Dutch municipalities have a legal obligation to provide a waste collection infrastructure for municipal waste, but they are free to choose whether to carry out this task themselves (own collection, municipal cooperation or neighboring municipality) or to contract out waste collection to outside firms (public or private). Of all observations, 36\% represent contracting out waste collection to a private firm and $23 \%$ to a public firm (see Table 1). It should be noted that a public firm operates under commercial law, whereas the shares are publicly owned by municipalities. A third group of observations (15\%) represents collection via a municipal service in cooperation with neighboring municipalities (see Bel et al. (2010)). For a fourth and rather small group (3\%), the waste is collected by a neighboring municipality. In the Netherlands, municipal cooperation means maintaining public production. The remaining observations $(22 \%)$ represent collection by municipalities themselves. Own collection is applied more in large cities and private collectors are used more in small municipalities (see also Dijkgraaf and Gradus (2013)).

Interestingly, the market share of public firms increased substantially from 5\% in 1998 to $34 \%$ in 2012 (see Figure 1). The share of municipalities collecting waste themselves decreased from $31 \%$ in 1998 to $17 \%$ in 2012 . In 1998, 43\% of municipalities used private firms, while this figure was $32 \%$ in 2012 . This fall was at least partly the result of the merging of small villages, as private collectors are especially active in these villages. 
Figure 1. Market shares, measured by number of municipalities

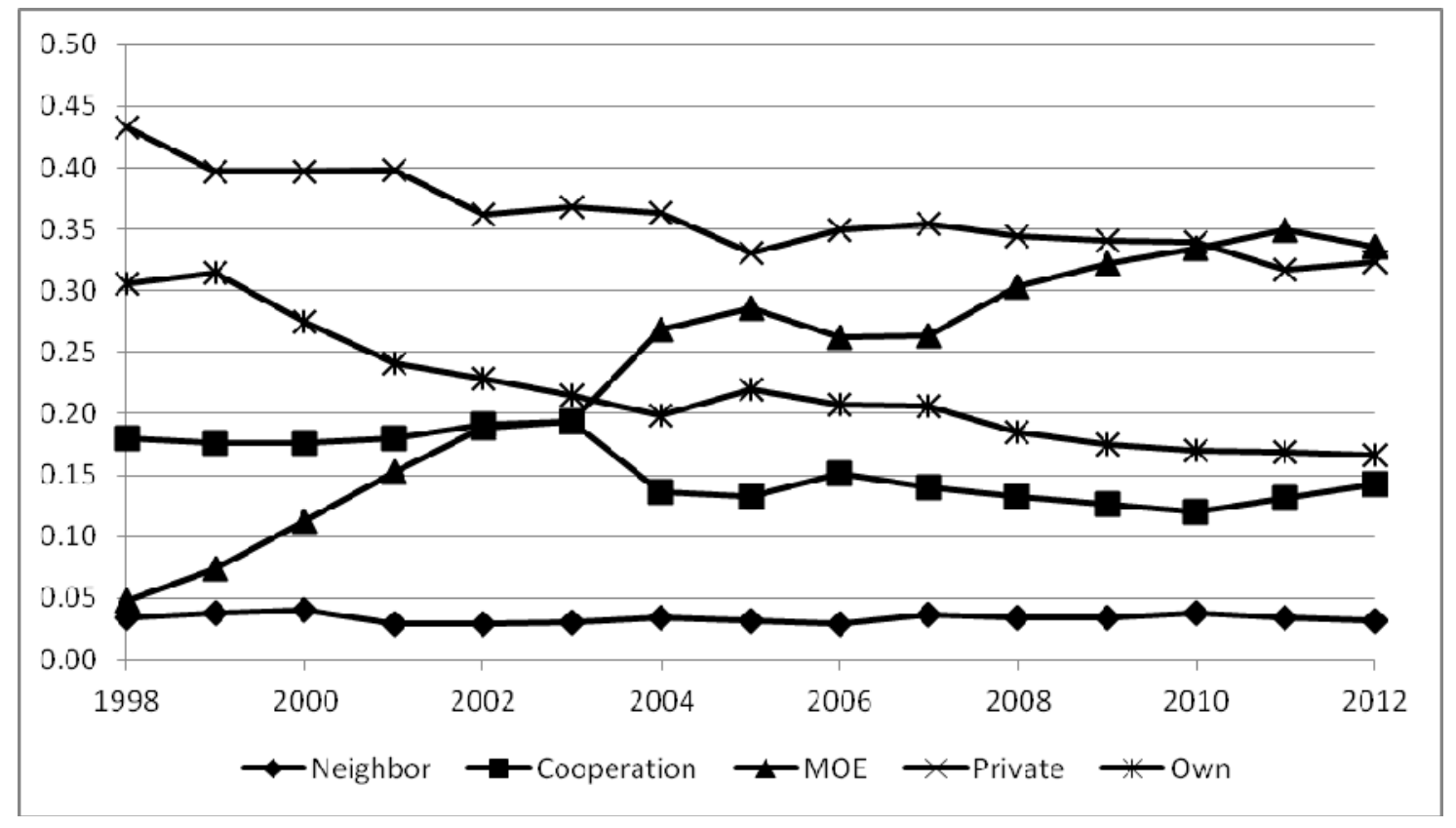

Figure 2. Number of municipalities with a unit-based pricing system

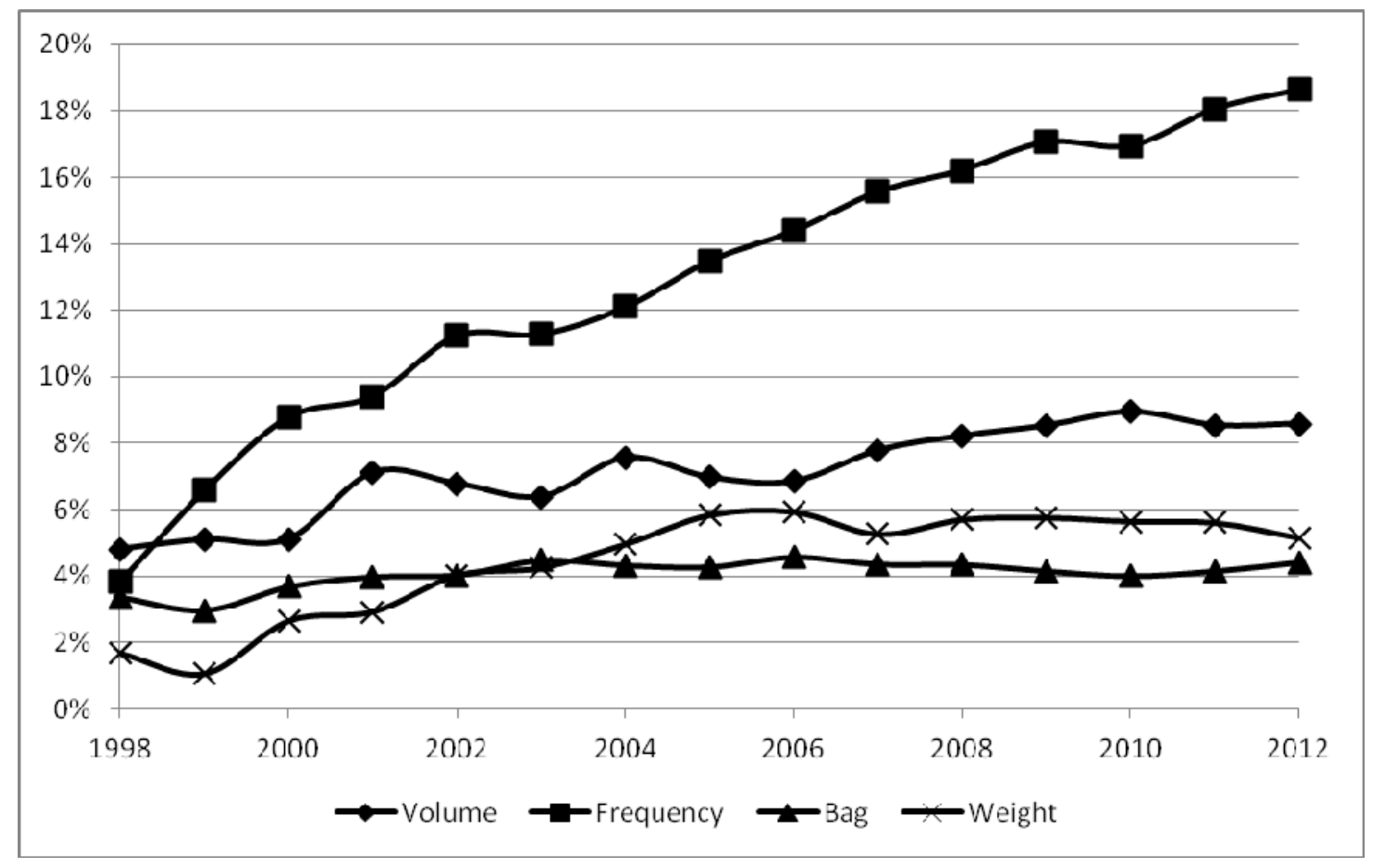


In this paper, we describe four different unit-based pricing (UBP) systems: volume, frequency, bag and weight. ${ }^{6}$ In some municipalities, ranging from $85 \%$ in 1998 to $63 \%$ in 2012, a flat-rate system has been used. The volume-based program allows households to choose between different volumes of collection bin; 5\% of Dutch municipalities in 1998 and 9\% in 2012 used this rather crude UBP system. A more refined marginal price results from a frequency-based system, in which the household pays for the number of times the bin is presented at the curbside. The share of municipalities using this system increased from $4 \%$ in 1998 to $19 \%$ in 2012 . In the bag-based system, households buy a special bag with specific marks. This is a more refined pricing system than the frequency-based one, as the volume of the bags is significantly less than that of the bins. Importantly, the bag system allows households to change volume each week. The share of municipalities with such a system is stable, at 4\% in 1998 and 2012. Maximum price incentives result from a weight-based system, pricing the waste per kilogram. The collection vehicle weighs the bin before emptying and combines this information with the identity of the owner, stored in a chip integrated in the collection bin. From Figure 2, it is clear that the use of the more refined weight-based system increased at the beginning of this century and stabilized after 2005 .

\section{Results}

Table 2 shows the estimation results for the cost function. All estimations are based on pooled ordinary least squares (OLS). Seven models are used to test the importance of institutional mode and unit-based pricing system in different settings:

- $\quad$ First, in the basic model, we include fixed effects for municipalities and we correct the standard deviation for clustered errors. ${ }^{7}$ This estimation will be used to divide between price and quantity effects in the next section.

- $\quad$ In the second model, we only include fixed effects for years and we present the corrected t-statistics.

- $\quad$ In the third model, we present the uncorrected t-statistics. As OLS estimates are still unbiased, only the standard errors will change.

In the literature, there has been some discussion about the endogeneity of the UBP variables (see Allers and Hoeben (2010) and Usui and Takeuchi (2013)). Therefore, to test for endogeneity ${ }^{8}$ of a UBP policy, we add four models:

\footnotetext{
${ }^{6}$ Some of the municipalities use a combination of these systems. We count these under the most refined system.

${ }^{7}$ In this case, it will be assumed that the standard errors for each municipality are not independently and identically distributed, that there is unknown correlation in $\varepsilon_{i, t}$ between municipalities in group $i$ within $t$, but that groups $i$ and $j$ do not have correlated errors (see Nichols and Schaffer (2007)).
} 
- $\quad$ Fourth, we try to capture the possible endogeneity of the UBP variables by using their lagged values in our estimation (see also Usui and Takeuchi (2013)).

- $\quad$ Fifth, we include a variable $U S^{9}$ representing the number of different waste streams collected by a municipality.

- $\quad$ Sixth, as we have fewer observations for US (3,034 instead of 6,655), we use these to estimate an alternative model without US, so that it is possible to check what the separate consequence of including this variable is.

- $\quad$ Seventh, we include an environmental activism dummy, which tests whether early movers are more environmentally orientated than municipalities that introduce unitbased pricing in later years (see Dijkgraaf and Gradus (2009)).

In all models, the estimate for the number of pick-up points (i.e. households) indicates constant returns to scale as the coefficient is very close to 1 . In section 5 , we will discuss the robustness of this assumption by using cost functions other than the Cobb-Douglas. In most models, household size has a positive and significant effect on total costs (except the model without fixed effects at municipal level). For area per household, we find a positive but insignificant relation (apart from the model without fixed effects at municipal level and the model including activism, for which the effect is negative and significant).

According to Table 2, the choice of unit-based pricing system is more important in saving costs than the choice of institutional mode. Let us give the results for the basic model. The cost advantage of introducing a system based on the volume of the collection is smallest, at $5.2 \%{ }^{10}$ The UBP system based on frequency reduces the total costs by $9.5 \%$. Notice that, based on cost reduction, the bag-based system is preferred to the weight-based system. The cost reduction is much smaller $(7.3 \%)$ for the weight-based system than for the bag-based system (12.4\%), as administrative costs are much higher for the weight system. In the next section, we elaborate on this issue. Note that if no fixed effects are taken into account, the

\footnotetext{
${ }^{8}$ Because of the unavailability of appropriate instrumental variables (IV), we employ OLS in our analysis while dealing with the possible endogeneity of the UBP variables by considering the bias caused by any omitted variable. Therefore, we include some different proxy variables.

${ }^{9}$ In the Netherlands in recent years, there has been an increase in facilities at refuse centers for collecting different waste streams such as construction and demolition waste and gravel (see also Dijkgraaf and Gradus (2014)).

${ }^{10}$ As the dependent variable is in logs, the effects of the pricing dummies are calculated using $\mathrm{e}^{x}-1$, where $x$ is the estimated coefficient.
} 
Table 2. Effect on waste collection costs: seven models

\begin{tabular}{|c|c|c|c|c|c|c|c|}
\hline & $\begin{array}{l}\text { (1) } \\
\text { Basic }\end{array}$ & $\begin{array}{c}(2) \\
\text { No munic.effects }\end{array}$ & $\begin{array}{c}\text { (3) } \\
\text { No clustered errors }\end{array}$ & $\begin{array}{c}(4) \\
\text { Lagged }\end{array}$ & $\begin{array}{c}(5) \\
\text { Policy change } \\
\end{array}$ & $\begin{array}{c}(6) \\
\text { Same data } \\
\end{array}$ & $\begin{array}{c}(7) \\
\text { Activism } \\
\end{array}$ \\
\hline Households & $1.004 * * *$ & $0.996 * * *$ & $1.004 * * *$ & $1.020 * * *$ & $1.025 * * *$ & $1.025 * * *$ & $0.995 * * *$ \\
\hline Household size & $0.380 * * *$ & -0.031 & $0.380 * * *$ & $0.491 * * *$ & $1.605 * * *$ & $1.609 * * *$ & -0.030 \\
\hline Population density & 0.006 & $-0.013 * * *$ & 0.006 & 0.020 & 0.032 & 0.032 & $-0.014 * * *$ \\
\hline UBP volume & $-0.053 * * *$ & $-0.038^{* * *}$ & $-0.053 * * *$ & $-0.056^{* *}$ & -0.033 & -0.033 & $-0.054 * * *$ \\
\hline - activism & & & & & & & $0.018^{* *}$ \\
\hline - 1-year lag & & & & -0.005 & & & \\
\hline UBP frequency & $-0.100 * * *$ & $-0.118^{* * *}$ & $-0.100 * * *$ & $-0.084 * * *$ & $-0.065 * *$ & $-0.065 * *$ & $-0.139 * * *$ \\
\hline - activism & & & & & & & $0.024 * * *$ \\
\hline - 1-year lag & & & & $-0.042 * *$ & & & \\
\hline UBP bag & $-0.132 * *$ & $-0.231 * * *$ & $-0.132 * * *$ & $-0.165^{* * *}$ & -0.071 & -0.070 & $-0.209 * * *$ \\
\hline - activism & & & & & & & -0.022 \\
\hline - 1-year lag & & & & 0.009 & & & \\
\hline UBP weight & $-0.076^{* *}$ & $-0.109 * * *$ & $-0.076^{* * *}$ & -0.050 & $-0.091 * *$ & $-0.091 * *$ & $-0.138 * * *$ \\
\hline - activism & & & & & & & $0.032 * *$ \\
\hline - 1-year lag & & & & $-0.058 * *$ & & & \\
\hline$U S$ & & & & & 0.001 & & \\
\hline Collection by neighbor & 0.003 & $0.044 * * *$ & 0.003 & 0.005 & 0.014 & 0.014 & $0.041 * * *$ \\
\hline Collection cooperation & -0.014 & $0.010^{*}$ & $-0.014^{*}$ & -0.009 & 0.006 & 0.006 & 0.008 \\
\hline Collection MOF & 0.018 & $0.030 * * *$ & $0.018^{* *}$ & $0.021^{*}$ & $0.028^{*}$ & $0.028^{*}$ & $0.030 * * *$ \\
\hline Collection private & -0.006 & $-0.029 * * *$ & -0.006 & -0.005 & 0.017 & 0.017 & $-0.031 * * *$ \\
\hline Constant & 0.462 & $0.856^{* * *}$ & $0.462 * * *$ & 0.333 & $-0.754 *$ & $-0.680^{*}$ & $0.841 * * *$ \\
\hline $\mathrm{R}^{2}$ & 0.974 & 0.977 & 0.974 & 0.973 & 0.953 & 0.953 & 0.977 \\
\hline Observations & 6,655 & 6,655 & 6,655 & 6,238 & 3,034 & 3,034 & 6,655 \\
\hline Clustered errors & Yes & Yes & No & Yes & Yes & Yes & Yes \\
\hline Fixed effects municipalities & Yes & No & Yes & Yes & Yes & Yes & No \\
\hline Fixed effects years & Yes & Yes & Yes & Yes & Yes & Yes & Yes \\
\hline
\end{tabular}

Note: $* * * * * / *$ indicates significance at $99 \% / 95 \% / 90 \%$. MOF stands for municipality-owned firms. 
effects of the frequency, bag and weight systems are much larger. Therefore, including fixed effects gives a more realistic picture of the effects of unit-based pricing systems (see also Allers and Hoeben (2010)). In addition, it is better to use clustered errors as this will take into account the special structure of our panel data.

Let us now discuss the cost advantages of the different institutional forms. The overall conclusion is that the effect of institutional mode is small and mostly not significant. If no fixed effects are taken into account, privatization has a significant downwards cost effect of 3\%. This is in line with Dijkgraaf and Gradus (2013), who show that positive privatization effects disappear if municipal fixed effects are taken into account. Interestingly, when we include these effects (column 3), there is a significant cost advantage of 1.4\% from intermunicipal cooperation, although it is very small. However, the significance disappears if clustered errors are taken into account. The difference between the basic model and the model without clustered errors is small as the only other coefficient that will no longer be significant (at the $95 \%$ level) is for collection by municipality-owned firms.

Results are quite similar among models 4, 5, 6 and 7, where we test endogeneity. We do find some evidence of an announcement effect from a UBP policy on waste reduction (model 4). The estimation results for model 5, where we include the variable $U S$, are quite similar to those of model 6, i.e. the basic model corrected for fewer observations due to including US. While we find some evidence of an announcement effect for the frequency-based system and the weight-based system, there is no such effect in the volume-based and bag-based systems. The announcement effect is driven by an environmental activism effect. Dutch municipalities that introduced frequency- or weight-based pricing early are more environmentally orientated than municipalities that introduced such pricing in later years (see also Linderhof et al. (2001) and Dijkgraaf and Gradus (2014)). This is confirmed by model 7, where we introduce an environmental activism dummy. ${ }^{11}$ This tests whether municipalities that have already introduced UBP had higher waste costs before introduction, because they were more environmentally friendly. Table 2 shows that there is an environmental activism effect for volume-, frequency- and weight-based pricing systems. However, this effect is relatively small compared with the overall effect of the relevant UBP system. The only problem with model 7 is that we have to exclude fixed effects as it is impossible to combine fixed effects

\footnotetext{
${ }^{11}$ The environmental activism dummy has the value 1 in all years for each municipality that introduces a specific unit-based pricing system (see also Dijkgraaf and Gradus (2009)).
} 
and the environmental activism dummy. ${ }^{12}$ Hereafter, we confine our discussion to the basic model (model 1).

In conclusion: as we have a large panel data set, it is important to correct for municipal fixed effects and clustered errors. When we do this, it is clear that the effects of unit-based pricing are much more important than the effects of institutional mode. Ranking the unit-based pricing systems according to their cost advantage gives (1) bag, (2) frequency, (3) weight and (4) volume.

\section{A division between price and quantity effects}

In this section, we divide the cost effect between price and quantity effects (see Table 3 ). ${ }^{13}$ To our knowledge, we are the first to describe these effects simultaneously. In the literature, much attention has been paid to quantity effects (see, for example, Kinnaman (2006) for an overview). Notice that as a consequence of this approach fewer observations are available $(4,942$ instead of 6,655). For example, data for 2012 are excluded for the costs estimation as no data are available for 2012 for waste quantity. Especially, the costs estimation of the bagbased pricing system in Table 3 is different from Table 2 . An explanation for this is that the number of observations for the bag-based pricing system (see also Figure 2).

From the literature, it is well known that unit-based pricing using the weight, bag or frequency system generates sizeable reductions in unsorted waste and other waste streams and an increase in recycling (see Dijkgraaf and Gradus (2014)). This is important for cost reduction, as the costs of incineration are approximately $60 \%$ of waste costs in the Netherlands. As a consequence, the institutional mode can only save collection costs, which are limited as they are on average $40 \%$ of total costs.

From Table 3, it can be seen that the weight system has the largest effect on quantities, reducing them by $29 \%$, followed by the frequency system (17\%), the bag system ( $8 \%)$. The effect of introducing a system based only on the volume of the collection is small (2\%). This result is not surprising since the volume-based system is less refined than the other systems.

\footnotetext{
${ }^{12}$ The fixed effects will capture parts of the environmental activism effect.

${ }^{13}$ Price is defined as total costs divided by total quantity. We will estimate $\ln Q$ and $\ln P$ with the same exogenous variables as equation (1).
} 
Table 3. A division between price and quantity effects

\begin{tabular}{|c|c|c|c|}
\hline & Costs & Quantity & Price \\
\hline Households & $1.024 * * *$ & $0.968 * * *$ & 0.056 \\
\hline Household size & $0.298^{*}$ & $1.039 * * *$ & $-0.742 * * *$ \\
\hline Population density & 0.008 & 0.002 & 0.006 \\
\hline UBP volume & $-0.053 * * *$ & $-0.018 * *$ & -0.035 \\
\hline UBP frequency & $-0.080 * * *$ & $-0.180 * * *$ & $0.100 * * *$ \\
\hline UBP bag & $-0.073 *$ & $-0.080 * * *$ & 0.008 \\
\hline UBP weight & $-0.077 * *$ & $-0.346^{* * *}$ & $0.269 * * *$ \\
\hline Collection by neighbor & 0.012 & 0.009 & 0.004 \\
\hline Collection cooperation & -0.010 & 0.013 & -0.023 \\
\hline Collection MOF & 0.014 & 0.009 & 0.005 \\
\hline Collection private & -0.008 & 0.013 & -0.021 \\
\hline Constant & 0.377 & $6.319 * * *$ & $-1.346^{* * *}$ \\
\hline $\mathrm{R}^{2}$ & 0.973 & 0.978 & 0.347 \\
\hline Observations & 4,942 & 4,942 & 4,942 \\
\hline Clustered errors & Yes & Yes & Yes \\
\hline Fixed effects municipalities & Yes & Yes & Yes \\
\hline Fixed effects years & Yes & Yes & Yes \\
\hline
\end{tabular}

Interestingly, the quantity effect is larger for the frequency-based system than for the bagbased system. Two disadvantages of the bag system are that Dutch legislation limits the number of bags carried per waste collection employee and that there is an incentive for households to put as much waste as possible in each bag, which makes them difficult to handle (see also Fullerton and Kinnaman (1996)). The same issues also make it hard to have a bag for compostable waste and therefore, in contrast to the other systems, the bag-based system is generally used for unsorted waste only. ${ }^{14}$ This point can be illustrated by Table 4 , where we divide the quantity effect into its important waste streams (unsorted, compostable and recyclable waste represented by paper, glass and textiles). The weight- and bag-based pricing systems reduce the amount of unsorted waste by more than the frequency- and volume-based pricing systems. However, only the weight- and frequency-based systems have a significant negative effect in reducing the amount of compostable waste. For the bag-based pricing system a significant increase of compostable waste takes place. This is a further indication that bag-based pricing systems will not be used for compostable waste. The UBP systems all increase the amount of recyclable waste collected. Thus, the overall conclusion is

\footnotetext{
${ }^{14}$ Allers and Hoeben (2010) illustrate that, in the Netherlands, the bag-based system is generally used for unsorted waste only.
} 
that the weight and frequency systems generate sizeable reductions in both unsorted and compostable waste.

Table 4. A division of the quantity effect into unsorted, compostable and recyclable waste

\begin{tabular}{|c|c|c|c|}
\hline & Unsorted & Compostable & Paper, glass and textiles \\
\hline Households & $0.954 * * *$ & $1.009 * * *$ & $0.972 * * *$ \\
\hline Household size & $1.027 * * *$ & $1.117 * * *$ & $1.065 * * *$ \\
\hline Population density & 0.008 & 0.020 & -0.007 \\
\hline UBP volume & $-0.063 * * *$ & 0.034 & $0.036^{*}$ \\
\hline UBP frequency & $-0.215^{* * *}$ & $-0.389 * * *$ & $0.081 * * *$ \\
\hline UBP bag & $-0.416^{* * *}$ & $0.152 * * *$ & $0.112 * * *$ \\
\hline UBP weight & $-0.447 * * *$ & $-0.785 * * *$ & $0.087 * * *$ \\
\hline Collection by neighbor & 0.016 & -0.003 & 0.022 \\
\hline Collection cooperation & 0.016 & 0.033 & 0.004 \\
\hline Collection MOF & 0.001 & $0.053 * *$ & 0.001 \\
\hline Collection private & 0.011 & $0.051 * *$ & 0.004 \\
\hline Constant & $5.779 * * *$ & $4.598 * * *$ & $4.687 * * *$ \\
\hline $\mathrm{R}^{2}$ & 0.953 & 0.706 & 0.946 \\
\hline Observations & 4,942 & 4,942 & 4,942 \\
\hline Clustered errors & Yes & Yes & Yes \\
\hline Fixed effects municipalities & Yes & Yes & Yes \\
\hline Fixed effects years & Yes & Yes & Yes \\
\hline
\end{tabular}

The price effects of the unit-based pricing dummies give some insights as well. The (average) price per kilogram of the volume-based system is somewhat lower than the price for the flatrate system and for bag-based pricing system is somewhat higher. For the frequency- and weight-based pricing systems, it is (substantially) higher with the largest price effect for the weight-based system. This is in accordance with the administrative costs of the different systems. In VROM (1997), there is an evaluation of the administrative costs of the weight-, bag- and frequency-based pricing systems in 12 Dutch municipalities. According to that study, yearly average administrative costs in 2012 prices are higher for the weight-based pricing system (20 euro per household) than for the other systems ( 9 euro for the bag-based system, 12 euro for the frequency-based system).

The division between price and quantity effects can also explain why the share of municipalities with bag- and weight-based pricing systems is quite stable and why the share of municipalities with a frequency-based system is increasing. A disadvantage of the weight- 
based system is the high administrative cost and a disadvantage of the bag-based system is that it is not easy to price compostable waste; the frequency-based system does not have such disadvantages.

\section{Alternative cost functions}

The overview paper by Simões and Marques (2012, p. 43) shows that $93 \%$ of the papers use a Cobb-Douglas technology and that other techniques are scarcely used. In sections 3 and 4, we assumed a Cobb-Douglas production technology. However, empirical findings in other sectors show that this specification might be too restrictive as it assumes constant scale effects (see also Dijkgraaf and Gradus (2008 ). To test this, we specify three alternative cost functions:

- a translog form;

- $\quad$ a flexible functional form (to the power 3);

- $\quad$ a Fourier flexible form.

Each alternative cost function has its advantages (and disadvantages). A translog function leads to a typical U-shape of the cost function. However, there could be more turning points and therefore we also estimate more flexible functional forms. The advantage of a Fourier specification or other flexible forms is its flexibility relative to alternative specifications, such as the Cobb-Douglas or translog cost function, and its robust foundation (see Gallant (1982)). However, the interpretation of a Fourier form or other flexible forms can be very complex. As far as we know, this comparison of different production technologies has never been applied before to waste collection cost functions.

The estimates of different cost functions are given in Table 5. The overall conclusion is that the assumption of constant scale effects seems too restrictive. ${ }^{15}$ For the translog form, there is a U-shaped curve, but the minimum is small at 15,000 households (see also Figure 3, which shows the estimated relation for the different specifications between the cost per household and the number of households in a municipality; the markers show the available observations and the lines give points lying between observations). For almost all Dutch municipalities, costs will increase if the number of households increases. Interestingly, in the flexible functional form and the Fourier form, there are more turning points. The intuition behind the flexible functional form is that the analysis often takes place at a higher level than the

\footnotetext{
${ }^{15}$ In this section, all estimates are without fixed municipality effects. If we include fixed effects, the scale patterns are less clear as the fixed effects will also capture parts of these different patterns.
} 
underlying technological processes. If these processes have different scale effects, the analysis at total cost level should take account of this heterogeneity. Costs increase for larger municipalities, of around 200,000 households, and decrease for municipalities with around 300,000 households, using the flexible functional form. It should be noted that the number of municipalities of this size is small and therefore we should be cautious with this interpretation. From Figure 3, it is clear that a Fourier cost equation can have more than one turning point, exhibiting something like a double M-shaped curve, for example. Interestingly, costs are low for municipalities of around 150,000 households, high for municipalities between 190,000 and 250,000, smaller again around 300,000 households, and larger again for bigger municipalities.

Figure 3. Cost of waste collection per household and number of households

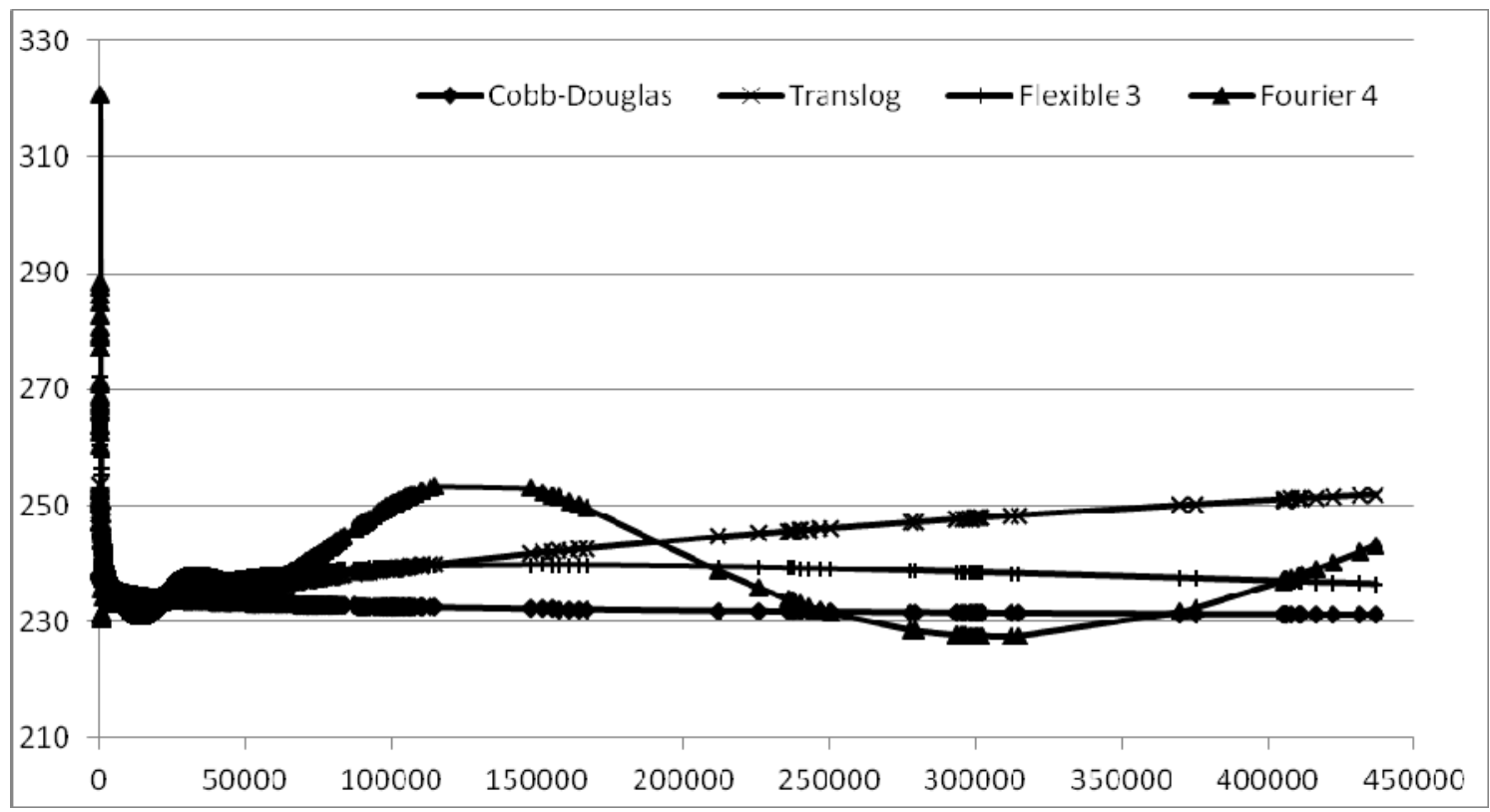

As we have estimated the models in this section without fixed effects, the estimation in Table 5 gives an unrealistic picture of the effects of unit-based pricing systems. Table 2 showed that if no fixed effects are taken into account, the effects of the frequency, bag and weight systems are much larger. Nevertheless, the estimations in this section are interesting as they show that the effect of dummies for the UBP system and for institutional form is independent of the cost function. Importantly, all our main conclusions of sections 3 and 4 with respect to unit-based pricing and institutional dummies are robust if another production technology, such as the Fourier specification, is used. 
Table 5. Effect on waste collection costs: different production technologies

\begin{tabular}{|c|c|c|c|c|}
\hline & Cobb-Douglas & Translog & Flexible & Fourier \\
\hline Households & $0.996 * * *$ & $0.875 * * *$ & 0.261 & 0.245 \\
\hline $0.5 *$ Households $^{2}$ & & $0.013 * * *$ & & $0.077 * * *$ \\
\hline Households $^{2}$ & & & $0.072 * * *$ & \\
\hline Households $^{3}$ & & & $-0.002 * * *$ & \\
\hline Cos(households) & & & & $-0.136 * *$ \\
\hline $\operatorname{Cos}(2 *$ households $)$ & & & & $-0.046 * * *$ \\
\hline $\operatorname{Cos}(3 *$ households $)$ & & & & $-0.024 * * *$ \\
\hline Cos( $4 *$ households $)$ & & & & $-0.015 * * *$ \\
\hline Sin(households) & & & & $-0.063 * * *$ \\
\hline $\operatorname{Sin}(2 *$ households $)$ & & & & $-0.038 * * *$ \\
\hline $\operatorname{Sin}(3 *$ households $)$ & & & & $-0.026 * * *$ \\
\hline $\operatorname{Sin}(4 *$ households $)$ & & & & $-0.016 * * *$ \\
\hline Household size & -0.031 & 0.011 & 0.027 & 0.037 \\
\hline Population density & $-0.013 * * *$ & $-0.014 * * *$ & $-0.014 * * *$ & $-0.014 * * *$ \\
\hline UBP volume & $-0.038 * * *$ & $-0.038 * * *$ & $-0.039 * * *$ & $-0.039 * * *$ \\
\hline UBP frequency & $-0.118 * * *$ & $-0.117 * * *$ & $-0.117 * * *$ & $-0.116^{* * *}$ \\
\hline UBP bag & $-0.231 * * *$ & $-0.230 * * *$ & $-0.229 * * *$ & $-0.231 * * *$ \\
\hline UBP weight & $-0.109 * * *$ & $-0.107 * * *$ & $-0.107 * * *$ & $-0.106 * * *$ \\
\hline Collection by neighbor & $0.044 * * *$ & $0.044 * * *$ & $0.046^{* * *}$ & $0.046 * * *$ \\
\hline Collection cooperation & $0.010^{*}$ & $0.010^{*}$ & $0.012 * *$ & $0.013 * *$ \\
\hline Collection MOF & $0.030 * * *$ & $0.030 * * *$ & $0.031 * * *$ & $0.030 * * *$ \\
\hline Collection private & $-0.029 * * *$ & $-0.028 * * *$ & $-0.027 * * *$ & $-0.027 * * *$ \\
\hline Constant & $0.845 * * *$ & $1.367 * * *$ & $3.248 * * *$ & $4.309 * * *$ \\
\hline $\mathrm{R}^{2}$ & 0.977 & 0.977 & 0.977 & 0.977 \\
\hline Observations & 6,655 & 6,655 & 6,655 & 6,655 \\
\hline Clustered errors & Yes & Yes & Yes & Yes \\
\hline Fixed effects municipalities & No & No & No & No \\
\hline Fixed effects years & Yes & Yes & Yes & Yes \\
\hline
\end{tabular}

Note: $* * * / * * / *$ indicates significance at $99 \% / 95 \% / 90 \%$. MOF stands for municipality-owned firms.

In Figures $4 \mathrm{a}-\mathrm{d}$, the confidence intervals of the scale effects for different production technologies are given. The solid black line represents the average estimated costs (with circles for the available observations and a line for points lying between observations), while the other lines represent the $95 \%$ confidence interval. It seems that scale effects are still present even when confidence intervals are taken into account. This conclusion is different from that of Dijkgraaf and Gradus (2008), where the confidence intervals are too wide to make rejection of a horizontal relationship between collection costs and number of households possible. However, that conclusion was based on a much smaller sample. 
Figure 4. Confidence intervals of scale effects by different production technologies a. Cobb-Douglas

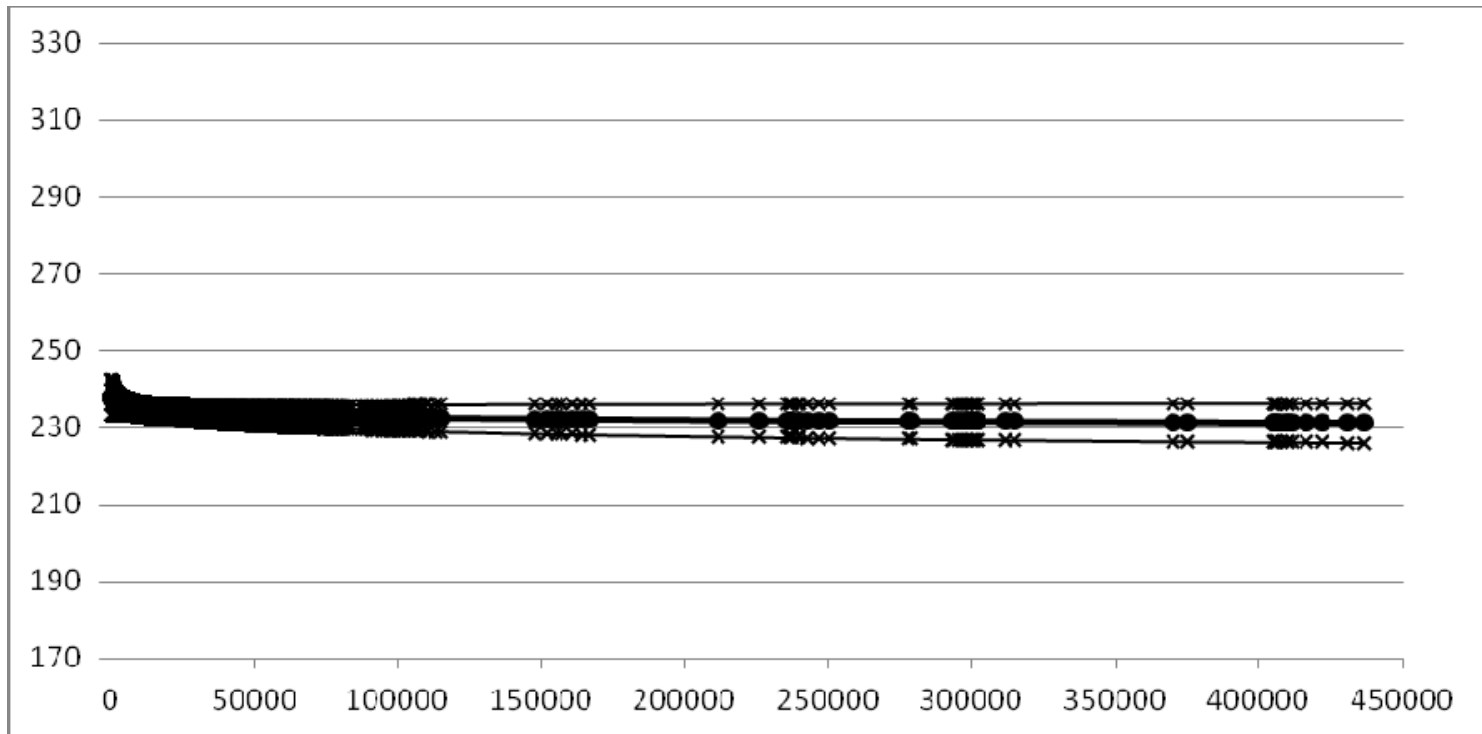

\section{b. Translog}

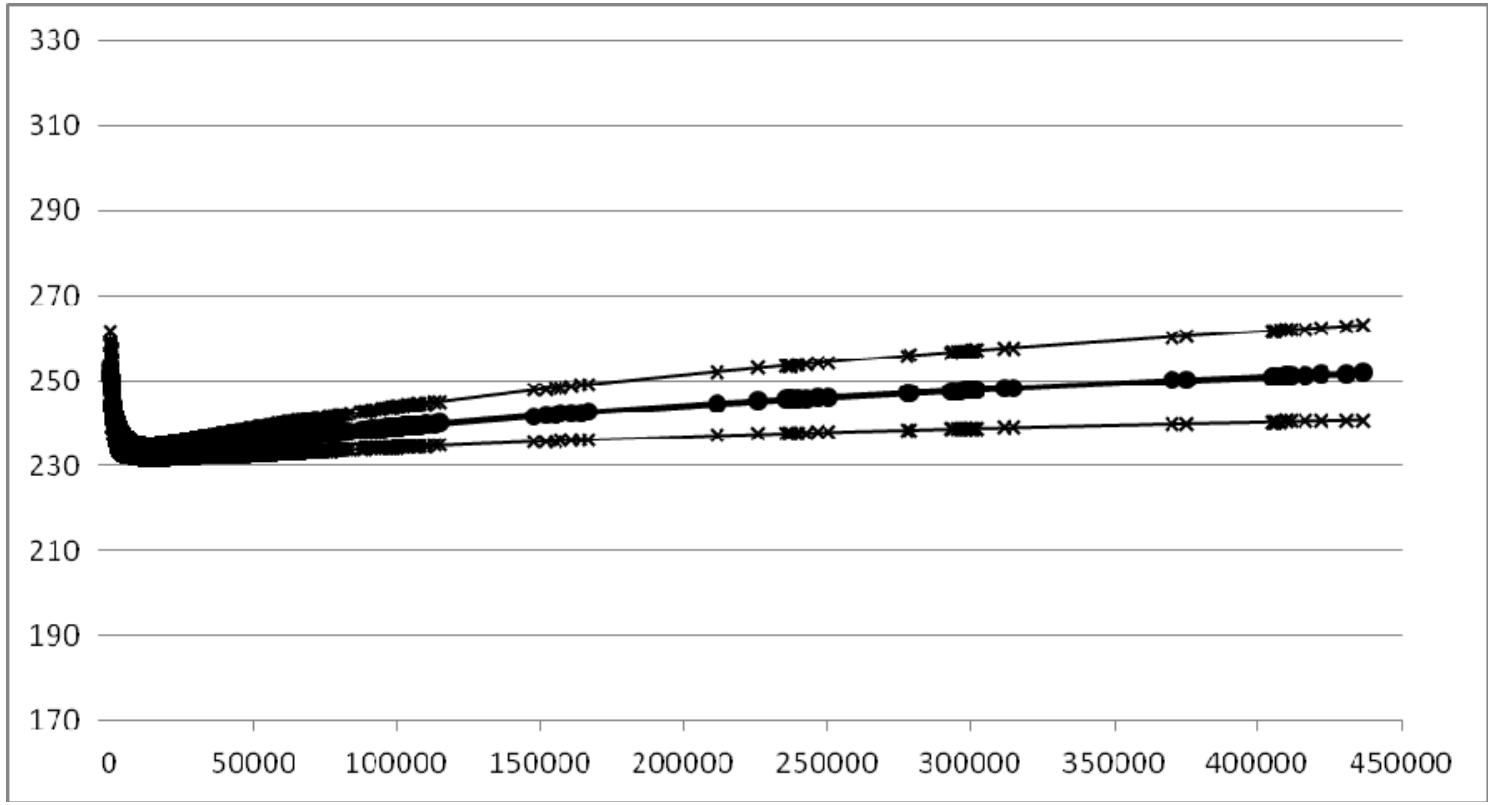




\section{c. Flexible}

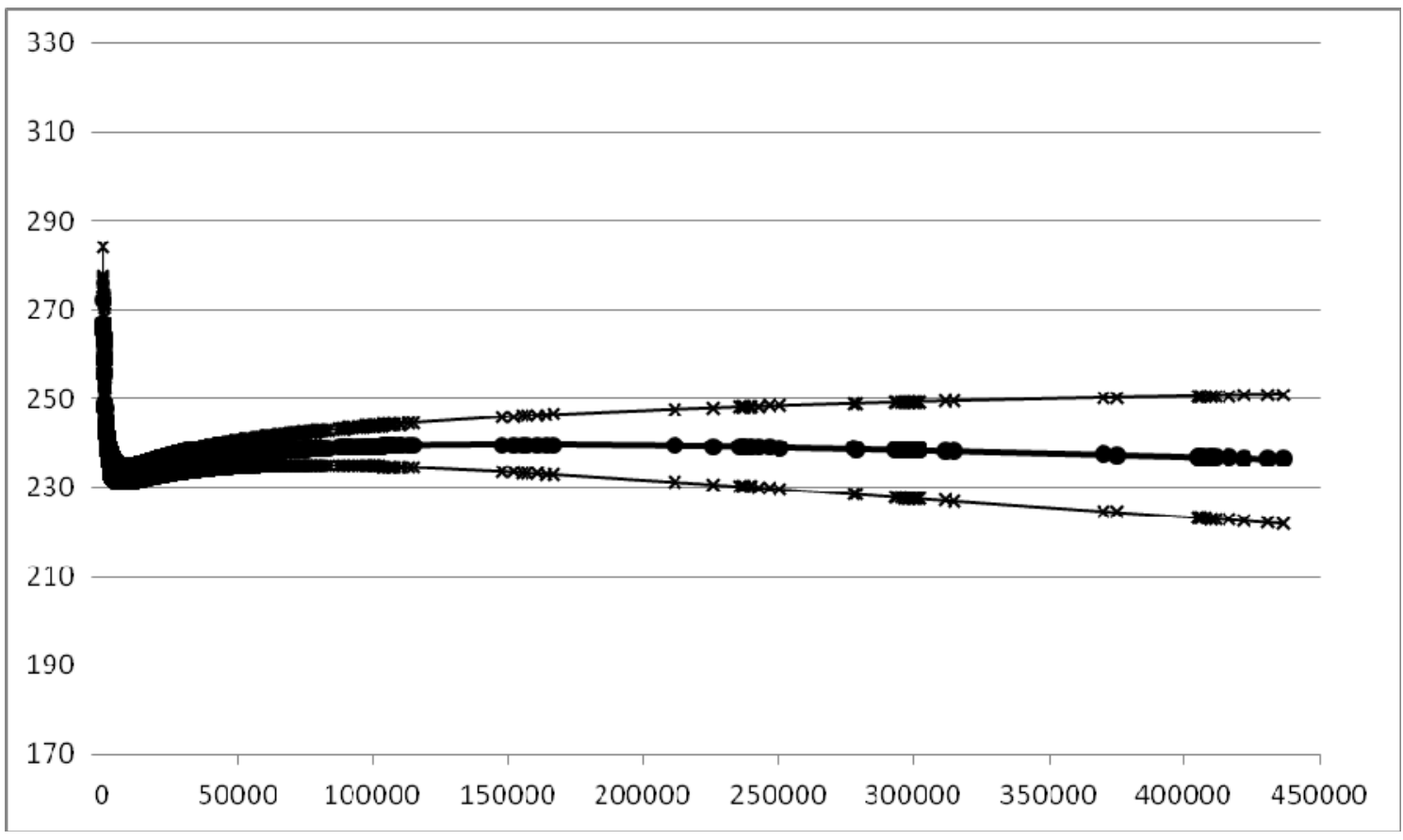

\section{d. Fourier}

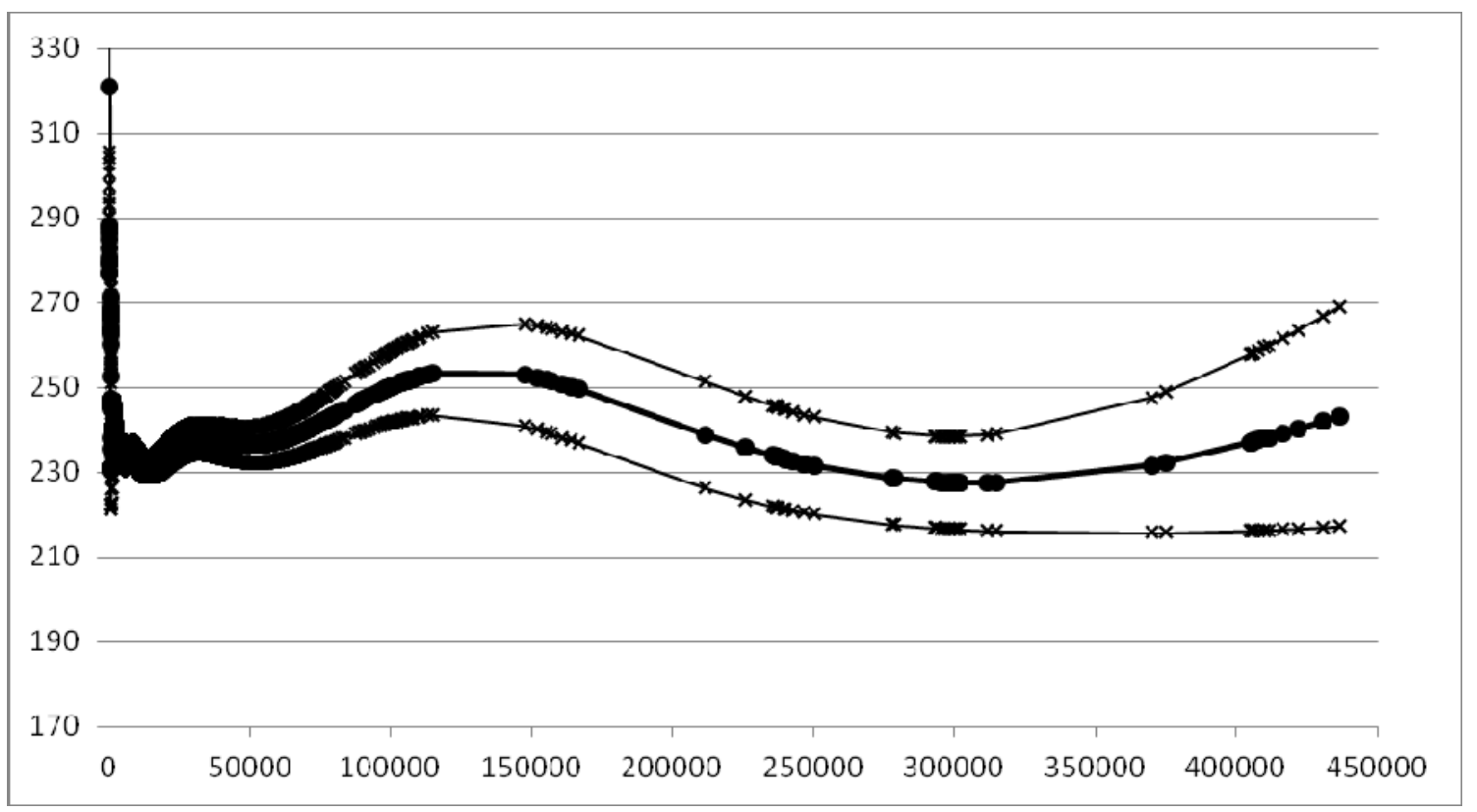

\section{Conclusions}

By using panel data for 1998-2012, we estimate the effect on waste collection costs of different institutional forms and unit-based pricing systems. We show that unit-based pricing 
systems such as the weight-, bag- and frequency-based systems are more important from a cost-minimizing point of view than the institutional mode of waste collection. By dividing between price and quantity effects, we give an explanation for the increase in the number of municipalities with a frequency-based system, as the reductions in unsorted and compostable waste are sizeable and the administrative costs of such a system are small and an explanation for the small amount of the bag-based system is that it is not easy to price compostable waste. By using different production technologies such as a translog or a Fourier specification, we give some indication that Dutch municipalities already make use of scale effects. Only for very small municipalities are there some scale effects. Furthermore, the choice of production function does not influence the estimates for the different dummies.

There are many avenues to explore in future research. First, it is important to collect more detailed information about the different unit-based pricing systems. The increasing number of municipalities with a frequency system is of special interest. In some municipalities, curbside collection of recyclables has expanded and households have to bring unsorted waste to pickup points. As it can be hard to collect cross-sectional data on these variables, case studies of different municipalities are a possibility as well. Also for municipalities with a bag system there can be interesting case studies as in some municipalities, such as Maastricht, the use of illegal lookalike bags is an issue (see also Dijkgraaf and Gradus (2014)). Second, it would be worthwhile to carry out a cost-benefit analysis of unit-based pricing methods or other recycling measures where externalities are taken into account. Third, one municipality's decisions can be influenced by a neighboring municipality's, and this can be tested using spatial models (see Brueckner (2003)). Fourth, it is important to study the interrelation between unit-based pricing systems and, for example, mandatory recycling as has been done by Yang and Innes (2007). 


\section{References}

Allers, M. and C. Hoeben (2010), 'Effects of unit-based garbage pricing: a differences-indifferences approach', Environmental and Resource Economics 45(3): 405-28.

Bel, G. and M. Warner (2013), 'Factors explaining inter-municipal cooperation: a metaregression analysis', paper presented at Public Management Research Association Conference, Madison/WI.

Bel, G., E. Dijkgraaf, X. Fageda and R.H.J.M. Gradus (2010), 'Similar problems, different solutions: comparing refuse collection in the Netherlands and Spain', Public Administration 88(2): 479-96.

Brueckner, J. (2003), 'Strategic interaction among governments: an overview of empirical studies', International Regional and Urban Economics 26(2): 175-88.

Callan, S.J. and J. M. Thomas (2001). 'Economies of scale and scope: a cost analysis of municipal solid waste services', Land Economics 77(4): 548-560.

Dijkgraaf, E. and R.H.J.M. Gradus (2003), 'Cost savings of contracting out refuse collection', Empirica 30(2): 149-61.

Dijkgraaf, E. and R.H.J.M. Gradus (2004), 'Cost savings in unit-based pricing of household waste: the case of the Netherlands', Resource and Energy Economics 26(2): 353-71.

Dijkgraaf, E. and R.H.J.M. Gradus (2008), 'Institutional developments in the Dutch waste collection market', Environment and Planning C: Government \& Policy 26(1): 110-26.

Dijkgraaf, E. and R.H.J.M. Gradus (2009), 'Environmental activism and dynamics of unitbased pricing systems', Resource and Energy Economics 31(1): 13-23.

Dijkgraaf, E. and R.H.J.M. Gradus (2013), 'Cost advantage cooperations larger than private waste collectors', Applied Economics Letters 20(7): 702-5.

Dijkgraaf, E. and R.H.J.M. Gradus (2014), 'Waste management in the Netherlands', in: T. Kinnaman and K. Takeuchi (eds), Handbook on Waste Management, Cheltenham (UK): Edward Elgar Publishers, forthcoming.

Domberger, S. and P. Jensen (1997), 'Contracting out by the public sector: theory, evidence, prospects', Oxford Review of Economic Policy 13(4): 67-78.

Fullerton, D. and T.C. Kinnaman (1996), 'Household responses to pricing garbage by the bag', American Economic Review 86(4): 971-84.

Gallant, A.R. (1982), 'Unbiased determination of production technologies', Journal of Econometrics, 20(2): 285-323.

Kinnaman, T.C. (2006), 'Examining the justification for residential recycling', Journal of Economic Perspectives 20(4): 219-32. 
Linderhof, V., P. Kooreman, M. Allers and D. Wiersma (2001), 'Weight-based pricing in the collection of household waste: the Oostzaan case', Resource and Energy Economics 23: 359-71.

Nichols, A. and M. Schaffer (2007), Clustered Errors in Stata, http://www.stata.com/meeting/13uk/nichols_crse.pdf.

Simões, P. and R. Marques (2012), 'On the economic performance of the waste sector. A literature review', Journal of Environmental Management 106: 40-7.

Stevens, B.J. (1978), 'Scale, market structure, and the cost of refuse collection', Review of Economics and Statistics 60(3):, 438-48.

Usui, T. and K. Takeuchi (2013), 'Evaluating unit-based pricing of residential solid waste: a panel data analysis', Environmental and Resource Economics, forthcoming.

VROM (1997), Ervaringen met tariefdifferentiatie en huishoudelijk afval ('Experience with differentiated tariffs and domestic waste'), Den Haag: Ministry of Environmental Affairs. Yang, H.L., Innes, R. (2007), 'Economic incentives and residential waste management in Taiwan: an empirical investigation' Environmental and Resource Economics 37: 489-519. 


\section{Appendix A. Definition of variables}

Costs (total)

Households

Household size

Population density

UBP volume

UBP frequency

UBP bag

UBP weight

UBP activism

US

Collection by neighbor

Collection cooperation

Collection municipality-owned firms

Collection private

Waste total

Waste unsorted

Waste biodegradable

Waste paper, glass and textiles costs in euro per municipality

number of households per municipality

number of inhabitants per household

area in square meters per household

dummy is 1 if volume-based pricing system is

present and 0 otherwise

dummy is 1 if frequency-based pricing system

is present and 0 otherwise

dummy is 1 if bag-based pricing system is

present and 0 otherwise

dummy is 1 if weight-based pricing system is

present and 0 otherwise

Dummy is 1 for all years if municipality

introduces UBP in later years

number of separate collected waste streams

dummy is 1 if waste is collected by

neighboring municipality and 0 otherwise

dummy is 1 if waste is collected by

cooperation of municipalities and 0 otherwise

dummy is 1 if waste is collected by

municipality-owned firm and 0 otherwise

dummy is 1 if waste is collected by private

firm and 0 otherwise

total quantity of collected waste (unsorted,

biodegradable, glass, paper, textiles) in tonnes

per municipality

total quantity of collected unsorted waste in

tonnes per municipality

total quantity of collected biodegradable waste

in tonnes per municipality

total quantity of collected paper, glass and

textile waste in tonnes per municipality 
(costs total divided by waste total) 